\title{
Engagement in mental health treatment among veterans returning from Iraq
}

This article was published in the following Dove Press journal:

Patient Preference and Adherence

12 March 2010

Number of times this article has been viewed

\section{Tracy Stecker ${ }^{1,2}$ \\ John Fortney ${ }^{3,4}$ \\ Francis Hamilton ${ }^{1,2}$ \\ Cathy D Sherbourne ${ }^{5}$ \\ Icek Ajzen ${ }^{6}$}

'Psychiatric Research Center, Dartmouth Medical School, Lebanon, $\mathrm{NH}$, USA; ${ }^{2}$ VA Health Services Research and Development, White River Junction Veterans Administration, White River Junction, VT, USA; ${ }^{\mathrm{V} A}$ Health Services Research and Development (HRS\&D), Center for Mental Health and Outcomes Research, Central Arkansas Veterans Healthcare System, North Little Rock, AR, USA; ${ }^{4}$ Division of Health Services Research, Department of Psychiatry, College of Medicine, University of Arkansas for Medical Sciences, Little Rock, AR, USA; ${ }^{5}$ RAND, Santa Monica, CA, USA; ${ }^{6}$ Department of Psychology, University of Massachusetts, Amherst, MA, USA

Correspondence: Tracy Stecker Psychiatric Research Center, Dartmouth Medical School, 2 Whipple Place Suite 202, Lebanon, NH 03766, USA

$\mathrm{Tel}+\mathrm{I} 6034480263$

Email tracy.stecker@dartmouth.edu
Objectives: Many veterans return from combat experiencing a variety of mental health concerns. Previous research has documented a stigma associated with seeking treatment that interferes with the decision to seek treatment. This study, conceptualized using the theory of planned behavior, assessed beliefs about mental health treatment in order to understand mental health treatment seeking behavior among a group of returning National Guard soldiers who served in the war in Iraq.

Methods: Participants were one hundred and fifty Operation Iraqi Freedom National Guard soldiers who screened positive for depression, posttraumatic stress disorder, generalized anxiety disorder, panic disorder or alcohol abuse disorder on the Mini International Neuropsychiatric Interview (MINI). Participants were asked to complete a questionnaire assessing beliefs about mental health treatment and treatment-seeking behavior.

Results: Beliefs related to symptom reduction and work were significantly related to mental health treatment-seeking behavior.

Conclusions: Interventions developed to engage veterans into care must be directed toward cognitive factors that motivate treatment seeking in addition to traditionally targeted structural barriers.

Keywords: treatment-seeking behavior, mental health

\section{Introduction}

The likelihood of military veterans experiencing mental health symptoms increases post-deployment, particularly for those who have combat-related experiences. ${ }^{1}$ About a quarter of recent war veterans receiving care in the Veterans Administration (VA) health care system report experiencing mental health problems. ${ }^{2}$ Recently returning veterans are at increased risk for experiencing mental health disorders, with soldiers returning from Iraq (Operation Iraqi Freedom [OIF]) being more likely to meet criteria for depression, anxiety, and/or posttraumatic stress disorder (PTSD) than soldiers returning from Afghanistan (Operation Enduring Freedom [OEF]). ${ }^{1}$ Rates of mental health symptoms for soldiers returning from Iraq were as high as $20 \%$ for PTSD, $18 \%$ for anxiety, and $15 \%$ for depression. ${ }^{1}$ A recent study by RAND reports prevalence rates for PTSD of $13.8 \% .{ }^{3}$ Given the high prevalence of mental health concerns among returning veterans, it is critical to promote the detection and treatment of these disorders in this population. Unfortunately, many returning veterans struggling with disabling mental health problems fail to initiate treatment. ${ }^{1}$ The present study was designed to explore the factors that influence veterans' decisions to seek treatment for these disorders as a basis for improving interventions to encourage treatment seeking. 
The conceptual framework for the study is the theory of planned behavior (TPB) ${ }^{4}$ which has been used successfully to explain and predict behaviors such as exercising, donating blood, adhering to a low-fat diet, using condoms for the prevention of HIV/AIDS, and using illegal drugs. ${ }^{5-10}$ According to the TPB, the decision to engage in any behavior can ultimately be traced to the person's beliefs about the behavior in question: beliefs about the likely consequences of the behavior (behavioral beliefs), beliefs about the normative expectations of others (normative beliefs), and beliefs about the presence of factors that may facilitate or prevent performance of the behavior (control beliefs). These beliefs produce a favorable attitude toward the behavior, result in perceived social pressure or subjective norm, and give rise to perceived behavioral control or the capability of performing the behavior. In combination, these constructs lead to the formation of a behavioral intention. Intention is assumed to be the immediate antecedent of behavior, and to guide behavior in a controlled and deliberate fashion. Finally, given a sufficient degree of actual control over the behavior, people are expected to carry out their intentions (Figure 1).

For the purpose of this study, we identified the behavior as seeking treatment from a physician or mental health specialist for the treatment of mental health concerns within one year after returning from the war in Iraq. The objective of the study was to determine which beliefs predict the intention to engage, as well as actual engagement in mental health treatment among OIF veterans.

\section{Methods}

\section{Sample and procedure}

Participants were members of the Army National Guard from a rural southern state who were deployed to Iraq for one year.
Participants had returned from their deployment approximately one year prior to study participation. Enrollment of participants occurred during monthly drill weekends at local armories. Participants were given information about the study through the chain of command. Two hundred sixty-eight veterans were screened for major depressive disorder, panic disorder, generalized anxiety disorder, PTSD and/or alcohol abuse disorder using the Mini International Neuropsychiatric Interview (MINI) ${ }^{10}$ One hundred and fifty (62\%) screened positive for one of the targeted disorders and all agreed to participate in the study. Participants were required to complete a 45 -item self-report measure and would be followed up at three months by phone to assess whether they had initiated mental health treatment in VA and/or non-VA settings with a physician or mental health specialist.

\section{Measures}

\section{MINI}

The $\mathrm{MINI}^{10}$ is a short structured diagnostic interview for DSM-IV psychiatric disorders. It has been documented as acceptable to patients and generally takes approximately 15-25 minutes to administer. ${ }^{11}$ It has been validated compared to the SCID and the CIDI, ${ }^{10}$ and is considered valid when administered by phone.

\section{Measuring intention}

To assess the intention to attend mental health treatment, the respondent was asked to respond to three items assessing intention on a seven-item scale. Intention items were scored by calculating the mean across the three items. ${ }^{12}$

\section{Measuring behavior}

Respondents were asked at the three-month follow-up whether they had sought treatment from a physician or mental

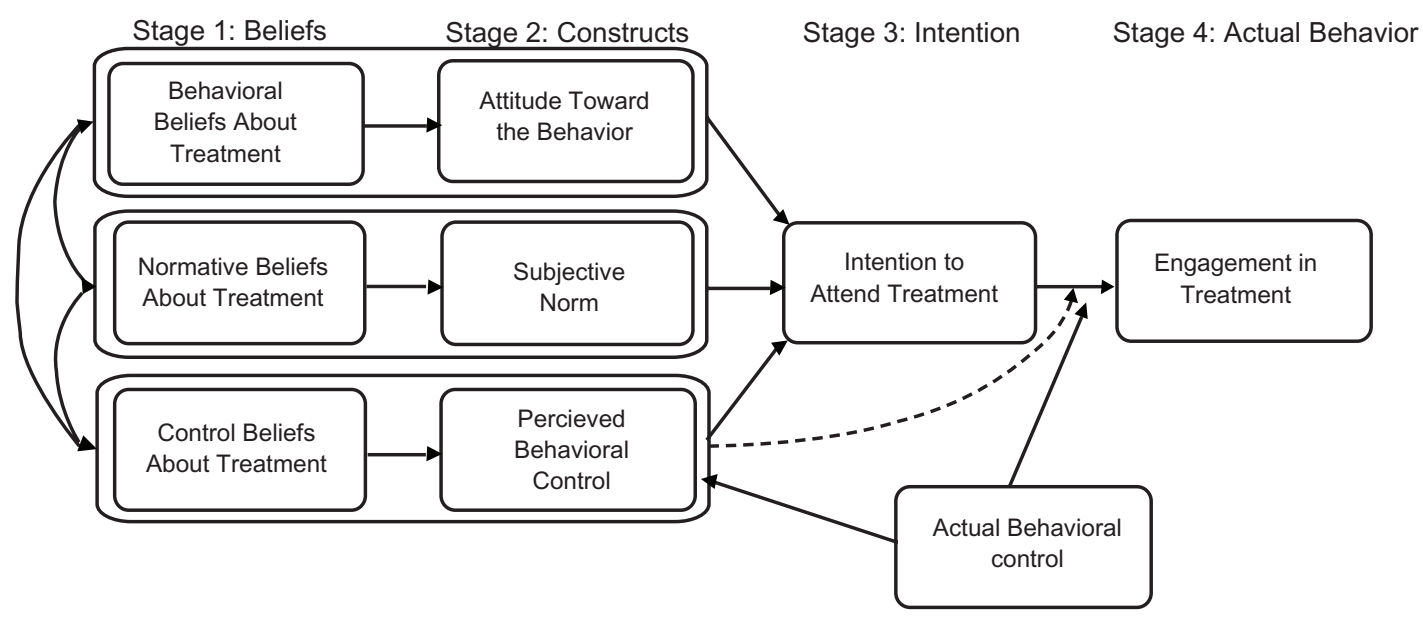

Figure I Theory of planned behavior. 
health specialist for the treatment of mental health concerns within one year after returning from the war in Iraq.

\section{Measuring behavioral, normative, and control beliefs}

Using recommended methods based on the TPB ${ }^{12}$ items were derived that reflect beliefs about mental health treatment most frequently raised in interviews with another sample of National Guard veterans who had served in Iraq and screened positive for one of the targeted mental health disorders. ${ }^{13}$ Six items assessing the strength of behavioral beliefs (treatment will reduce symptoms; people will think I'm crazy if I go to treatment; going to treatment means I can't handle my problems; going to treatment will hurt my work career; going to treatment will hurt my military career; treatment will help me identify triggers and cope better) were weighted by how important the outcome of the belief was to the individual (outcome evaluation). An example of weighted item would be that an individual reported that treatment would reduce symptoms $(+7)$ and that this was an extremely important outcome for them $(+3)$, leading to a weighted score of $+21(+7 \times+3=21)$.

A similar weighting method was used for three normative beliefs (my family; people I work with: my friends would approve of my going to mental health treatment) and four control beliefs (It is difficult to talk about my experiences in treatment; I am comfortable talking to a mental health specialist; I can easily travel to treatment; I could make time for treatment). The sums of the weighted beliefs create a composite belief score representing an indirect measurement of each of the attitude, subjective norm, and perceived behavioral control constructs.

\section{Measuring attitude, subjective norm, and perceived behavioral control}

Four items assessed attitude toward treatment (Alpha $=0.93$; two-week test-retest $=0.83$, three items assessed subjective norm (Alpha $=0.69$; two-week test-retest $=0.46)$ and three items assessed perceived behavioral control (Alpha $=0.63$; two-week test-retest $=0.55$ ).

Additional items requested participants to identify demographic information such as gender, ethnicity and age, as well as actual behavioral controls such as insurance status, travel distance to clinic, and transportation availability.

\section{Data analysis}

All data was processed and managed using SPSS software (version 13.0; SPSS Inc., Chicago, IL). To identify predictive beliefs of both the intention to engage in treatment and actual treatment attendance, a two-stage model was developed. In the first stage, we tested whether direct measures of the constructs were related to intention. One linear regression model was specified with the dependent variable as the intention scale score and the three explanatory variables as the direct measures of each construct (the attitude scale, subjective norm scale, and perceived behavioral control scale). In the second stage, we determined which of the weighted beliefs items were related to intention and actual treatment. Only beliefs associated with constructs (attitudes, subjective norm, and perceived behavioral control) that were significantly related to intention were considered for the second stage of the analyses. Two regressions were specified, one linear regression with intention specified as the dependent variable and each of the corresponding weighted beliefs specified as the explanatory variables, the other a logistic regression with actual engagement in treatment as the dependent variable.

Finally, we tested whether intention predicted mental health treatment attendance at baseline. One logistic regression was used with the dependent variable as actual attendance and the explanatory variable as the intention scale score. Demographic variables were included in all the regression equations.

\section{Results}

Characteristics of the sample are in Table 1. Participants ranged in age from 20 to 59 years with a mean age of 31 years and the majority were male (88\%). More than half of the participants $(62 \%)$ screened positive for more than one of the targeted mental health disorders. While many of the participants reported problematic mental health symptoms after returning from war, only $35 \%$ had been to see a mental health professional about their symptoms. Of these, $21 \%$ were prescribed a psychotropic medication.

Table I Characteristics of the sample $(N=150)$

\begin{tabular}{ll}
\hline Variable & N (percentage of sample) \\
\hline Male & $132(88 \%)$ \\
African-American & $48(32 \%)$ \\
Screened positive for major depression & $54(36 \%)$ \\
Screened positive for panic disorder & $44(29 \%)$ \\
Screened positive for generalized anxiety & $71(47 \%)$ \\
disorder & $86(57 \%)$ \\
Screened positive for alcohol abuse & $65(43 \%)$ \\
Screened positive for PTSD & $93(62 \%)$ \\
Screened positive for more than one & \\
disorder & $52(35 \%)$ \\
Been to mental health treatment & $31(21 \%)$ \\
Prescribed a psychotropic medication &
\end{tabular}

Abbreviation: PTSD, posttraumatic stress disorder. 
In stage one, we tested whether the direct measures of the constructs predicted the intention to engage in treatment. Two of the three constructs were significant including attitudes $(P=0.000)$ and perceived behavioral control $(P=0.000)$, and together explain $41 \%$ of the variation in intention.

In stage two, we first examined bivariate relationships between beliefs and intention. Of the beliefs associated with attitudes and perceived behavioral control (the two scales predictive of intention), six beliefs were significantly correlated with intent to seek treatment: that treatment would relieve problematic symptoms $(\mathrm{r}=0.440, P=0.000)$, that treatment would hurt their work $(\mathrm{r}=0.226, P=0.005)$, that it would be difficult to discuss some of their symptoms $(\mathrm{r}=0.245, P=0.003)$, that they had transportation $(\mathrm{r}=0.298$, $P=0.000$ ), that they were comfortable talking to mental health professionals $(\mathrm{r}=0.305, P=0.000)$, and that they had time to seek treatment $(\mathrm{r}=0.293, P=0.000)$.

In multivariate analyses, two beliefs remained significant: the belief that treatment would reduce symptoms $(P<0.003)$ and that treatment would hurt their work career $(P<0.026)$, as shown in Table 2. Similar results were obtained for the regression with actual treatment engagement as the dependent variable.

Finally, we tested to see whether the intention to seek treatment was related to actual engagement into treatment. In this model, intention was significantly related to engagement $(P=0.000)$ and explained $29 \%$ of actual engagement. Actual control (ie, travel distance and insurance status) and diagnostic variables were not significant.

\section{Discussion}

Overall, we found that specific beliefs about mental health treatment differentiated between those seeking treatment versus those who did not. Specifically, veterans who reported

Table 2 Weighted beliefs predictive of intention

\begin{tabular}{ll}
\hline Beliefs & $P$ value \\
\hline Treatment will reduce symptoms & $0003^{* *}$ \\
People will think I'm crazy if I go to treatment & 0954 \\
Going to treatment means I can't handle my problems & 0763 \\
Going to treatment will hurt my work career & $0026^{*}$ \\
Going to treatment will hurt my military career & 0370 \\
Treatment will help me identify triggers and cope better & 0286 \\
It is difficult to talk about my experiences in treatment & 0250 \\
I am comfortable talking to a mental health specialist & 0798 \\
I can easily travel to treatment & 0075 \\
I could make time for treatment & 095 I \\
\hline
\end{tabular}

Notes: $* P<0.05 ; * * P<0.000$. that treatment would result in an improvement in bothersome symptoms and those who reported that treatment would hurt their work career were significantly more likely to both intend to engage in treatment and to have attended treatment.

The results of the present study provide valuable information regarding reasons for low rates of mental health treatment seeking among returning veterans. Interventions designed to improve access to care must focus on cognitive aspects of treatment seeking. In general, veterans who intended to seek care were more likely to report that they believed that treatment would help their symptoms, had time and transportation to talk to a mental health specialist, and were comfortable with the idea of talking to a specialist.

On the other hand, veterans who intended to seek care were also more likely to report two negative consequences to treatment seeking: difficulty talking about some aspects of their experience in war and thought that going to treatment would hurt their work career. Given that many of the veterans who sought care screened positive for PTSD, it is probably not surprising that veterans who sought care reported difficulty processing their experiences in treatment. This is a double-edged sword in some respects for veterans given that seeking treatment implies discomfort with symptoms while "treatment" would necessitate a re-processing of traumatic war events. Likewise, veterans who sought treatment may have experienced unanticipated consequences to their work. As with any nonwork meeting scheduled within work hours (ie, medical care, dental care, mental health care, etc.), there may be consequences to the job. This would be particularly true for mental health treatment, which requires more than one visit.

The measure used for this study was developed based on previous work with this population and conceptualized from the TPB. The scoring mechanism used in this measure was complicated although we were able to identify predictive beliefs to treatment seeking. Test-retest alpha coefficients for the attitude, subjective norm, and perceived behavioral control subscales were reported. Two of the subscales reported lower alpha coefficients and the measure were subsequently modified so that problematic items were removed from the measure. Removal of the problematic items resulted in higher alpha coefficients than were reported here.

Our findings are limited by the fact that assessment was conducted in one National Guard unit, and may not generalize to other geographical areas or other branches of the military. In addition, there was a high rate of screening positive for one of the targeted mental health disorders in this study as compared to other studies such as Hoge's. ${ }^{1}$ Since veterans participating in this study were told that screening 
information would be kept confidential and not linked to future research, they may have provided a more accurate picture of their symptoms. Another potential methodological limitation is that the assessment was conducted after veterans had been home from war for at least one year, which gave veterans time to seek treatment. Ideally it would be important to assess beliefs about treatment seeking when an individual is experiencing distressful symptoms, prior to a decision to seek treatment. Since it would be difficult at best to design this type of study, we choose to allow veterans a time period postdeployment for the assessment.

Findings from this study suggest that interventions developed to increase engagement for mental health treatment should focus on cognitive factors associated with treatmentseeking behavior. Evidence-based practices such as those associated with cognitive-behavioral principles or motivational interviewing may be ideally suited toward increasing engagement. At the same time, the military may need to address policies so that work careers are not affected negatively should veterans engage in mental health treatment.

\section{Disclosures}

This work was funded by grant number R34 MH078898-01. The authors report no conflicts of interest in this work.

\section{References}

1. Hoge CW, Castro CA, Messer SC, McGurk D, Cotting DI, Koffman RL. Combat duty in Iraq and Afghanistan, mental health problems, and barriers to care. $N$ Engl J Med. 2004;351:13-22.

2. Kang HK, Hyams KC. Mental health care needs among recent war veterans. $N$ Engl J Med. 2005;352(13):1289.
3. RAND. Invisible Wounds of War: Psychological and cognitive injuries, their consequences, and services to assist recovery. Santa Monica, CA: RAND; 2008.

4. Ajzen I. The Theory of Planned Behavior. Organ Behav Hum Decis Process. 1991;50:179-211.

5. Hardeman W, Johnston M, Johnston D, Bonetti D, Wareham N, Kinmonth A. Application of the Theory of Planned Behaviour in behaviour change interventions: A systematic review. Psychol Health. 2002;17(2):123-158.

6. Jemmott JB, Jemmott LS, Fong GT. Abstinence and safer sex HIV risk-reduction interventions for African American adolescents: A randomized controlled trial. JAMA. 1998;279:1529-1536.

7. Murphy WG, Brubaker RG. Effects of a brief theory-based intervention on the practice of testicular self-examination by high school males. J School Health. 1990;60:459-462.

8. Brubaker RG, Fowler C. Encouraging college males to perform testicular self-examination: evaluation of a persuasive message based on the revised theory of reasoned action. J Appl Soc Psychol. 1990;20: $1411-1422$.

9. Conner M, Sparks P. Theory of planned behaviour and health behaviour. In: Conner M ed. Predicting health behaviour: Research and practice with social cognition models. 2nd ed. Buckingham, UK: Open University Press; 2005. p. 170-222.

10. Sheehan DV, Lecrubier Y, Sheehan KH, et al. The Mini-International Neuropsychiatric Interview (M.I.N.I.): the development and validation of a structured diagnostic psychiatric interview for DSM-IV and ICD-10. J Clin Psychiatry. 1998;59(Suppl 20):22-33.

11. Pinninti NR, Madison H, Musser E, Rissmiller D. MINI International Neuropsychiatric Schedule: clinical utility and patient acceptance. Eur Psychiatry. 2003;18(7):361-364.

12. Francis JJ, Eccles MP, Johnston M, et al. Constructing Questionnaires Based on the Theory of Planned Behaviour. A Manual for Health Services Researchers. Newcastle upon Tyne, UK: Quality of Life and Management of Living Resources; 2004.

13. Stecker T, Fortney J, Hamilton F, Ajzen I. An assessment of beliefs about mental health care among veterans who served in Iraq. Psychiatr Serv. 2007;58:1358-1361.
Patient Preference and Adherence

\section{Publish your work in this journal}

Patient Preference and Adherence is an international, peer-reviewed, open access journal that focusing on the growing importance of patient preference and adherence throughout the therapeutic continuum. Patient satisfaction, acceptability, quality of life, compliance, persistence and their role in developing new therapeutic modalities and compounds to

\section{Dovepress}

optimize clinical outcomes for existing disease states are major areas of interest. This journal has been accepted for indexing on PubMed Central. The manuscript management system is completely online and includes a very quick and fair peer-review system. Visit http://www.dovepress.com/ testimonials.php to read real quotes from published authors. 